\title{
Quantitative determination of total Phenolic and Tannin contents of Murraya koenigii Twigs
}

\author{
Shruthi Shree Gandhi $\mathrm{S}^{1}$ *and Dr.Dhinek. $\mathrm{A}^{2}$ \\ Department of Biochemistry, Sri Ramakrishna College of Arts and Science for Women, New \\ Siddhapudur, Coimbatore-641044, Tamilnadu.
}

\begin{abstract}
The total phenolic and tannin content present in the ethanolic extracts of Murrayakoenigii twigs was estimated in this study. The ethanolic extracts of Murrayakoenigii twigs phenolic and tannin contents were measured using Folin-Ciocalteu's method. Folin-Ciocalteu's method. Works on the basis of oxidation and reduction reaction with single electron transfer with gallic acid and tannic acid taken as standards. The study revealed the presence of a significant amount of phenolic and tannin content in the ethanolic extracts of Murrayakoenigii twigs.
\end{abstract}

Keywords: Murrayakoenigii twigs, Tannin, Phenolic acids, Secondary metabolites, Total phenolic content.

\section{Introduction}

Murrayakoenigii also known as curry tree is a perennial shrub that is native to India and is also grown in Malaysia, Sri lanka, South Africa and other parts of the Asian subcontinent. The twigs and leaves of curry tree contain phytochemicals and other minerals that are essential for the diet and are also responsible for their medicinal properties. Which was used to treat various ailments since ancient times in India. [2] The twigs of the Murrayakoenigii tree are sometimes used as chewing sticks in Tamilnadu,India.The twigs of the curry tree is enriched with phytochemicals such as alkaloids, flavonoids, carbohydrates, amino acids and phenols and minerals such as calcium and magnesium.[6]

The presence of Phenolic acids in plants are responsible for their color, flavor and medicinal property. These Phenolic compounds also exhibit antioxidants, Anti-inflammatory activity, anticancer and antibacterial activity for the plant and the living beings that feed on them.[8][9] Thus, these biologically active molecules serve as readily available drugs to treat various ailments. The phenolic contents present in plants are very well known to play an essential role in providing protection against the free radicals generated in the living system. [3][4] Free radicals are said to cause various types of cancers such as oral cancer, breast cancer, lung cancer and other serious disorders in living beings. [5][10].Besides, the tannins and other phenolic acids present in plants are said to provide the plant a natural defense system from predators. Tannins are responsible for their aroma, flavour and colour of the plant which is also the reason for their exploitation for commercial purposes. 


\section{Materials and methods}

\section{Sample preparation:}

The plant sample is prepared by air drying the twigs for 3 days and was made in to fine powder. A conical flask was taken with the dried powder weighed and was added with Ethanol. The mixture is incubated at room temperature for two days following frequent agitation of the mixture. The supernatant was collected by filtering with Whatman no:1filter paper. The solvents were stored, evaporated and weighed for further analysis.

\section{Phytochemical analysis:}

Test for carbohydrates (Molisch's test): $2.0 \mathrm{ml}$ of the plant extract were taken and few drops of 5\% of alpha naphthol solution was added to it. The mixture was shaken and added few drops conc.H2SO4 along the sides of the test tube. Appearance of violent ring at the junction of two layers of the solution indicates the presence of carbohydrates.

Test for alkaloids: To $2.0 \mathrm{ml}$ of the plant extract 1 or 2 drops of Mayer's reagent was added. Appearance of white creamy precipitate at the bottom of the test tube indicates the presence of alkaloids.

Test for phenols: To $2.0 \mathrm{ml}$ of the plant extract $5 \%$ ferric chloride was added and observed for the appearance of deep blue colour which indicates the presence of phenols.

Test for Phytosterol: To $1.0 \mathrm{ml}$ of plant extract, $2.0 \mathrm{~m} 1$ of chloroform and few drops of acetic anhydride and concentrated sulfuric acid was added. The solution changes to bluish green color precipitate which indicates the presence of phytosterols.

Test for flavonoids: To $2 \mathrm{ml}$ of the plant extract few drops of $10 \%$ ferric chloride was added. Appearance of green or blue colour indicates the presence of flavonoids.

Test for tannins: Ferric chloride test: To $1.0 \mathrm{ml}$ of the plant extract added few drops of $10 \%$ ferric. The formation of black colour precipitate will indicate the presence of tannins.

Test for Saponin: To $2.0 \mathrm{~m} 1$ of the plant extract, $6.0 \mathrm{~m} 1$ of water was added and the mixture was shaken vigorously. The formation of foam indicates the presence of saponins.

Test for amino acids: To $2.0 \mathrm{~m} 1$ of the plant extract, few drops of ninhydrin reagent was added and observed for the development of violet or purple colour which indicates the presence of amino acids.

Test for Steroid: To $1.0 \mathrm{~m} 1$ of the plant extracts $2.0 \mathrm{ml}$ of chloroform and $0.2 \mathrm{~m} 1$ of concentrated sulfuric acid was added. The formation of red colour precipitate will indicate the presence of steroid.

*Corresponding Author 
Test for cardiac glycosides: To $2.0 \mathrm{ml}$ of the plant extract few drops of concentrated sulphuric acid was added. Appearance of red color precipitate indicates the presence of cardiac glycosides.

\section{Determination of total Phenolic content}

Total Phenolic content: The total phenolic content was determined by using Folin-Ciocalteu assay. (Singleton et al.) A volume of $0.5 \mathrm{ml}$ of the plant extract $(100 \mu \mathrm{g} / \mathrm{mL})$ was mixed with $1.5 \mathrm{ml}$ of the 1:10 Folin-Ciocalteu reagent. The reaction was made to stand for 5 minutes and was added with $1.5 \mathrm{ml}$ of $7 \%$ of sodium carbonate solution. The solution is made up to $10 \mathrm{ml}$ with distilled water. The reaction mixture was incubated at room temperature for $30 \mathrm{mins}$. The appearance of blue color was measured at $765 \mathrm{~nm}$ using spectrophotometer with Gallic acid equivalent per gram of dry plant extract (GAE/g) used as standard for plotting the graph.

Total Tannin content: The total tannins contents were determined by the Folin-Ciocalteu method. To the $0.1 \mathrm{~mL}$ of the sample extract, $0.5 \mathrm{~mL}$ of Folin-Ciocalteu reagent was added. To the mixture 1 $\mathrm{ml}$ of $35 \%$ sodium carbonate was added and made up to $10 \mathrm{ml}$ with distilled water. The mixture was incubated at room temperature for 30 mins and the absorbance was measured at $700 \mathrm{~nm}$ with tannic acid equivalents per gram of dry plant extract (TAE/g) as standard at concentrations (100, 200, 300, $400,500 \mu \mathrm{g} / \mathrm{ml})$. [7]

\section{Results}

Phytochemical constituents such as flavonoids, alkaloids, tannins are present in ethanol extracts. Carbohydrates is present in both the chloroform and ethanol extracts. amino acids and phytosterols were present in the chloroform extracts.

Table 1. Phytochemical Constituents Present in the Plant Sample

\begin{tabular}{|c|c|c|}
\hline Phytochemicals & $\begin{array}{c}\text { Etha } \\
\text { nol }\end{array}$ & $\begin{array}{c}\text { Chlorofor } \\
\text { m }\end{array}$ \\
\hline Alkaloids & + & - \\
\hline Amino acids & - & + \\
\hline Carbohydrates & + & + \\
\hline $\begin{array}{c}\text { Cardiac } \\
\text { glycosides }\end{array}$ & - & - \\
\hline Flavonoids & + & - \\
\hline Phenols & + & + \\
\hline Phytosterols & - & - \\
\hline Saponins & - & - \\
\hline Steroids & + & - \\
\hline Tannins & + & - \\
\hline
\end{tabular}

$(+)=$ Presence of phytochemicals

$(-)=$ Absence of phytochemicals 


\section{Total Phenolic content:}

Table 2 shows the total phenolic contents which were calculated using the following linear equation $y=0.003 x, R^{2}=0.97$ obtained from the calibration curve of Gallic acid standard. Percentage of yield of the twig extracts was found to be $0.34876 \mathrm{mgGAe} / \mathrm{g}$ of sample.

Table 2. Comparison of Total Phenolic content of Sample at Five Different Concentrations with the Standard.

\begin{tabular}{|c|c|}
\hline $\begin{array}{c}\text { Gallic } \\
\text { Acid } \\
\text { (Standard } \\
\text { ) }\end{array}$ & Absorbance \\
\hline 100 & 0.15 \\
\hline 200 & 0.72 \\
\hline 300 & 1.15 \\
\hline 400 & 1.55 \\
\hline 500 & 1.98 \\
\hline $\begin{array}{c}\text { Murraya koenigii } \\
\text { twig extracts } \\
\text { (1000 } \boldsymbol{\mu g} / \mathbf{m l})\end{array}$ & 1.33 \\
\hline
\end{tabular}

\section{Total Tannin content:}

Table 3 shows the total tannin contents which were calculated using the following linear equation $y$ $=0.001 \mathrm{x}, \mathrm{R}^{2}=0.964$ obtained from the calibration curve of tannic acid standard. Percentage of yield of the twig extracts was found to be $1.386334746 \mathrm{mgTAE} / \mathrm{g}$ of sample. 
Table 3. Comparison of Total Tannin content of Sample at Five Different Concentrations with the Standard.

\begin{tabular}{|c|c|}
\hline $\begin{array}{c}\text { Tannic acid } \\
\text { (Standard) }\end{array}$ & Absorbance \\
\hline 100 & 0.15 \\
\hline 200 & 0.24 \\
\hline 300 & 0.35 \\
\hline 400 & 0.41 \\
\hline 500 & 0.59 \\
\hline $\begin{array}{r}\text { Murraya } \text { koenigii } \\
\text { twig extracts }\end{array}$ & 1.52 \\
(1000 $\boldsymbol{\mu g} / \mathbf{m l})$ & \\
\hline
\end{tabular}

\section{Acknowledgement:}

The authors are grateful to Sri Ramakrishna College of Arts and Science for Women, New

Siddhapudur, Coimbatore- 44 .

\section{Reference:}

1) Andressa Blainski, Gisely Cristiny Lopes and João Carlos Palazzo de Mello *, Application and Analysis of the Folin Ciocalteu Method for the Determination of the Total Phenolic Content from Limonium Brasiliense L, Molecules, 18, 6852-6865. June (2013).

2) Balakrishnan R, Vijayraja D, Jo SH, Ganesan P, Su-Kim I, Choi DK., Medicinal Profile, Phytochemistry, and Pharmacological Activities of Murraya koenigii and its Primary Bioactive Compounds. Antioxidants (Basel). Jan (2020).

3) Kumar N, Goel N. Phenolic acids: Natural versatile molecules with promising therapeutic applications. Biotechnol Rep (Amst).Aug(2019).

4) Njeru, Sospeter \& Matasyohb, Josphat \& Mwanikic, Charles \& Maina, Mwendia \& Kobiad, George.A Review of some Phytochemicals commonly found in Medicinal Plants. International Journal of Medicinal Plants. (2013).

5) Pham-Huy LA, He H, Pham-Huy C. Free radicals, antioxidants in disease and health. Int J Biomed Sci. (2008). 
6) Shruthi Shree Gandhi S and Dr.Dhinek.A,Phytochemical analysis, Antioxidant activity and Anti-inflammatory activity of Murraya koenigii Twigs. Journal of University of Shanghai for Science and Technology. Volume 23, Issue 4, April (2021).

7) Singleton VL, Orthofer R, Lamuela-Raventós RM. Analysis of total phenols and other oxidation substrates and antioxidants by means of folin-ciocalteu reagent. Methods in Enzymology. (1998).

8) Balakrishnan R, Vijayraja D, Jo SH, Ganesan P, Su-Kim I, Choi DK. Medicinal Profile, Phytochemistry, and Pharmacological Activities of Murraya koenigii and its Primary Bioactive Compounds. (2020).

9) Ghasemzadeh A, Jaafar HZ, Rahmat A, Devarajan T. Evaluation of Bioactive Compounds, Pharmaceutical Quality, and Anticancer Activity of Curry Leaf (Murraya koenigii L.).(2014)

10) Phaniendra A, Jestadi DB, Periyasamy L. Free radicals: properties, sources, targets, and their implication in various diseases. Indian J Clin Biochem.(2015). 